\title{
CHARACTERISTIC MICROSTRUCTURE OF MICRO HOT ROLLED PLATE STEEL VARIATING THE RADIUS OF BENDING TREATMENT WITH QUENCHING AND TEMPERING HEAT TREATMENT
}

\author{
Achmad Taufik ${ }^{1,2^{*}}$, Agus Suprapto ${ }^{1}$, Ahmad As'ad Sonief ${ }^{1}$ \\ ${ }^{1}$ Department of Mechanical Engineering Faculty of Engineering, Brawijaya University, Malang, Indonesia \\ ${ }^{2}$ Department of Mechanical Engineering FTI National Institute of Technology, Malang, Indonesia
}

HRP Steel is heat treatable material that is manufactured by Krakatu Company Steel Indonesian, which the specifi cation of HRP steel is classifi ed as an armor 2nd class. To get the hardness and high strength, it is quenched (by heating it up to austenite temperature and held for a few moments, then cooled with water at $T{ }^{\circ} \mathrm{C}$ ). Then the HRP Steel is heat treated again tempering (by heating it up to a certain temperature below the eutectoid line and retained for a while, then cooled with atmospheric air media) to improve its ductility. The purpose of this heat treatment is to improve the microstructure that can affect the value of hardness. There are two additional (?) methods used in this research fortreatmentof that material: mechanical bending treatment with radius $55 \mathrm{~mm}$ and $60 \mathrm{~mm}$. Analysis of the results of research shows that bending treatment and heat treatment modifies the morphology of microstructure. In the $55 \mathrm{~mm}$ bending radius treatment and quenching-tempering treatment, a microstructure formed of martensite structure that has higher percentage and has the form of a smooth martensite structure so that the value of Vickers hardness number is higher than the other treatment of $453 \mathrm{VHN}$ treatment.

Key words: Bending; Heat Treatment; Microstructur

\section{INTRODUCTION}

Material selection in manufacturing defense system main equipment (defense equipment) should be in accordance with its function, the material must have optimal physical properties and be able to withstand the impact of bullets. During this time steel armor is a material that has optimal ballistic properties [1].ballistic performance Armor's based on the nature of the hardness, the higher the hardness, the better the ballistic performance. The main consideration of the use of steel in the military has ground power to penetration. The optimum properties of armor steel are determined by toughness and yield strength. Armorsteel types of quenched and tempered Steels widely used in highly stressed structures such as hull and turret combat vehicles [2].

HRP Steel is a heat treatable steel product of PT. Krakatau Steel Indonesia, HRP Steel specifications are classified as steel armor. To get high hardness and strength, HRP Steel is heated to temperature austenite and held for a while and then cooled with water (quenching), the result is a high hardness steel called Quenched HRP Steel (QHRP Steel).

To increase ductility, QHRP is heated to a certain temperature below the line eutectoid and held for a while and then cooled with atmospheric air. The results of high and tough steel are called hardened Qenching and Tempering. However, Q \& T HRP Steel has a maximal hardness, due to the existence of structures austenite that do not transform to martensite fully. process constraints Quenching of large-sized material, a lot of decreased temperature austenite when entering the water quencher so that violence is not maximal.
Quenched steel has the highest strength and hardness limits but low ductility. Distortion occurs during the formation of martensite platelets which leads to increased strength and hardness [3]. To maintain the strength of quenched martensite for industrial scale it was tempered at temperatures between $150{ }^{\circ} \mathrm{C}-200{ }^{\circ} \mathrm{C}$ [4].

Q \& T Steel is steel which is produced from hot plate steel (HRP Steel), then quenched with aqueous media to increase the hardness followed by tempering to obtain ductility. The result of the process is steel that has high hardness and strength called armor steel.

Steel is a polycrystalline substance containing microstructure such as austenite, martensite and grain boundaries ferritic [5,6]. Martensite can be formed if steel is austenitized and cooled at high speed to avoid the formation of ferrite, pearlite and bainite as stated in the Diagram Continuous Cooling Transformation [7,8]. Q \& T Steel is widely used in the military because it has high hardness, strength ratio and good toughness. $[9,10]$. Besides that steel has good ballistic and mechanical properties, namely a combination of strength, plasticity and violence $[11,12]$. Increased Q \& T steel hardness occurs due to content low-carbon steel, which causes steel hardness to be maximum $[13,14]$.

The microstructure contained in steel can change depending on the temperature of the heat treatment and cooling treatment. Heat treatment temperature was obtained from $\mathrm{Fe}-\mathrm{C}$ diagram analysis to obtain the desired microstructure [15].

Fig. 1 shows the Fe-C phase diagram seen at a temperature of $727^{\circ} \mathrm{C}$, the austenite phase transformation 


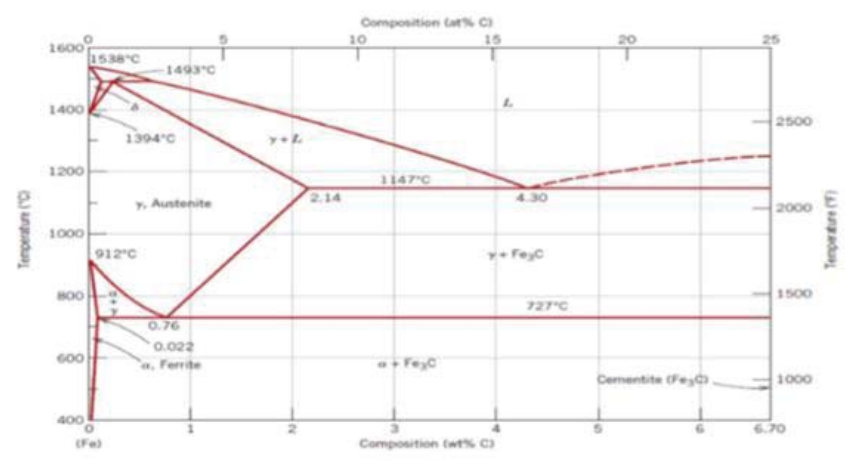

Figure 1: Phase diagram

becomes perlite phase. This phase transformation is known as the eutectoid reaction which is the basic phase of the heat treatment process in steel. At temperatures of $912^{\circ} \mathrm{C}$ to $1394^{\circ} \mathrm{C}$ shows gamma iron ( $\left.\mathrm{\gamma}-\mathrm{Fe}\right)$ or austenite, austenite has a FCC (Face Centered Cubic) Crystal structure that is stable, soft, resilient and easily formed. At a temperature of 1147 o $\mathrm{C}$ gamma iron can dissolve the maximum carbon element up to $2.14 \%$, the temperature below $727^{\circ} \mathrm{C}$ pure iron is in the ferrite $(\alpha-\mathrm{Fe})$ phase with a BCC (Body Centered Cubic) crystal structure, pure iron $\mathrm{BCC}$ is able to dissolve maximum carbon is around $0.02 \% \mathrm{C}$ at a temperature of $727^{\circ} \mathrm{C}$. Whereas iron delta $(\mathrm{Fe}-\mathrm{Fe})$ is formed from gamma iron which undergoes structural changes from FCC to BCC structure due to temperature increase from $1394^{\circ} \mathrm{C}$ to $1538^{\circ} \mathrm{C}$, in this phase iron delta is only able to absorb carbon at $0.05 \% \mathrm{C}$.

In the $\mathrm{Fe}-\mathrm{C}$ phase diagram there are several phase changes, namely changes in ferrite phase ( $\alpha-F e)$, aus-

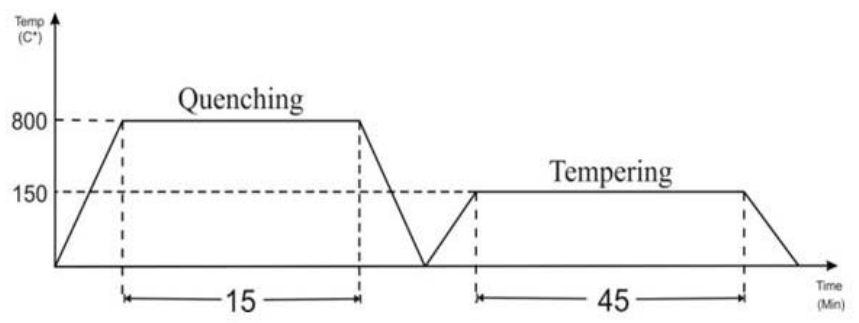

Figure 2: Quenching - Tempering visualization

tenite ( $\mathrm{y}-\mathrm{Fe})$, cementite, perlite, bainite and martensite. Ferrite is a solid solution of carbon in a pure iron structure that has a BureCC (Body Centered Cubic) structure with soft and ductile properties. The ferrite phase begins to form at temperatures between $300^{\circ} \mathrm{C}$ and reaches a temperature of $727^{\circ} \mathrm{C}$. Solubility of carbon in this phase is relatively small compared to solubility in other solid solution phases. When the ferrite phase is formed, the solubility of carbon in alpha iron is only about $0.02 \% \mathrm{C}$.

The austenite phase is a solid solution of intertition between carbon and iron which has a FCC (Face Centered Cubic) structure. The austenite phase is formed between $912^{\circ} \mathrm{C}$ temperature and $1394^{\circ} \mathrm{C}$ temperature. Solubility of carbon when it is in the austenite phase is greater until it reaches carbon solubility of around $2.14 \%$ C.
The novelty of this research is the hardness caused by changes in granules through the austenite temperature closest to the transformation line Ar3. The problem that arises in this study is how to increase the hardness by changing the martensitic microstructure on the hot roll steel plate so that the hardness reaches $\geq 500 \mathrm{BHN}$.

\section{Materials and Methods}
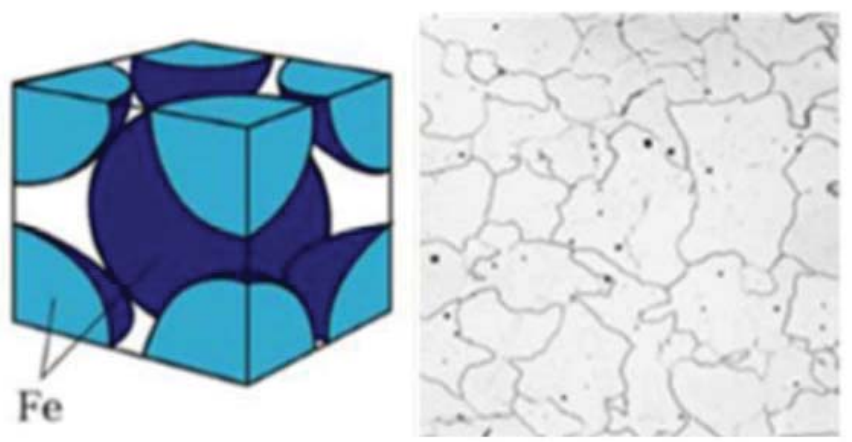

Figure 3: Microstructure of steel in ferit phase

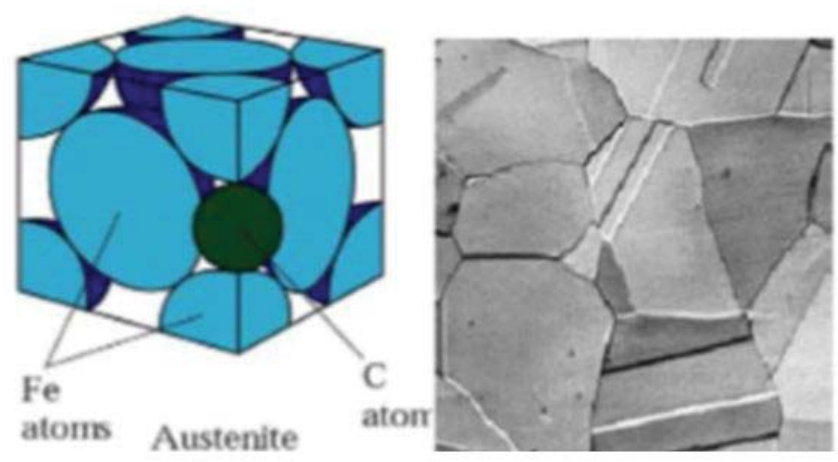

Figure 4: Microstructure of steel in austenit phase

In this study, looking for causes - effects that occur in each treatment given to Hot Rolled Plate Steel (HRPS). Material is obtained with a certificate listed in the chemical composition in order to maintain the truth and accuracy of the data. Material research was obtained from PT. Krakatau Steel is identical to ASTM A-570 Grade 30-50 which is classified as low carbon steel with a $\mathrm{C}$ content of $0.29 \%$.

This study used an experimental method, the indepen-

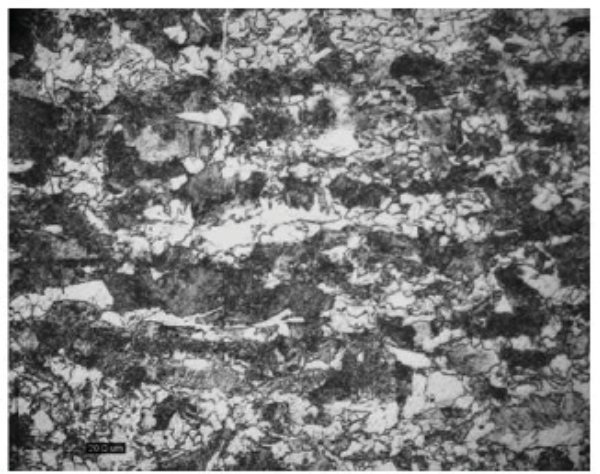

Figure 5: Microstructure before heat treatment 
dent variables used were bending radius and heat treatment (Quench and Temper), the dependent variable was the morphology of the microstructure and the value of hardness obtained from the results of hardness testing using the Vickers method. Quench $800{ }^{\circ} \mathrm{C}$ temperatures with a holding of 15 minutes and cooling water. While the temperature tempered $150{ }^{\circ} \mathrm{C}$ with a holding of 45 minutes.

Test preparation phase, 1) material is bended with a radius of $55 \mathrm{~mm}$ and $60 \mathrm{~mm}, 2$ ) hardness test of steel plate, 3 ) heat treatment. Hardness testing aims to determine changes in each material treatment. The material that has been formed is given a quench, tempered and quench-tempered heat treatment.

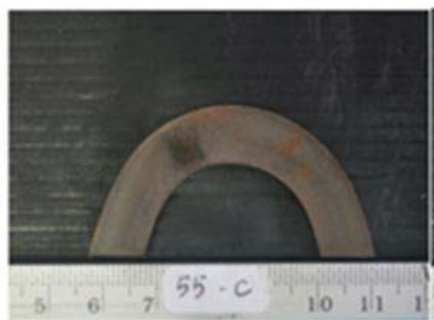

(a)

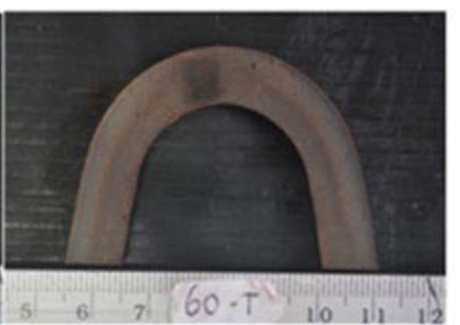

(b)
Figure 6: Material bending radius

(a) $55 \mathrm{~mm}$ and (b) $60 \mathrm{~mm}$

Metallographic examination aims to see and analyze the type and shape of microstructure after undergoing a heat treatment process in order to compare the microstructure of each specimen, metallographic specimens and for hardness testing.

To observe the microstructure, the test specimen is cut at the end. Experiments carried out on Metallography testing:

1. Specimens that have been cut and framed (mounted) grinded with grades 400, 600, 800, 1000, 1500.

2. The results of grinding, the specimens are polished with magnesium oxide $(\mathrm{MgO})$ so that there are no scratches on the surface of the specimen.

3. $3 \%$ nital etching is poured in a container and the specimen is dipped into etching for 5-30 seconds. The process of processing by dipping for $\pm 10 \mathrm{sec}$ onds in the digital solution is then washed with clean water and then dried.

4. Microstructure observation was carried out using the OLYMPUS BX41M optical microscope which was connected to the program on the computer. The specimen is placed on a test plane or microscope table and then brought closer to an optical microscope.

5. With an enlargement of 50 to 200 times, and taking photos of each specimen. Focusing on the microscope is rotated to get a good observation of each specimen.

6. After getting the right focus and lighting, take a photo from the specimen by clicking on the Capture frame icon in the program.

\section{Results and Discussion}

Effect of Bending Radius on HRP Steel Microstructure.

From the results of research conducted, with different bending angles morphological tests with hardness test research data in previus studies as morphological analysis reference with hardness properties.

Figure 10, morphologically the microstructure undergoes changes in each change in bending treatment size. The appearance of the $55 \mathrm{~mm}$ bending ferrite structure (fig. 10.a) has a greater density compared to $60 \mathrm{~mm}$ bending (fig. 10.b). This is because the ferrite structure bending treatment moves to dock with other ferrite structures

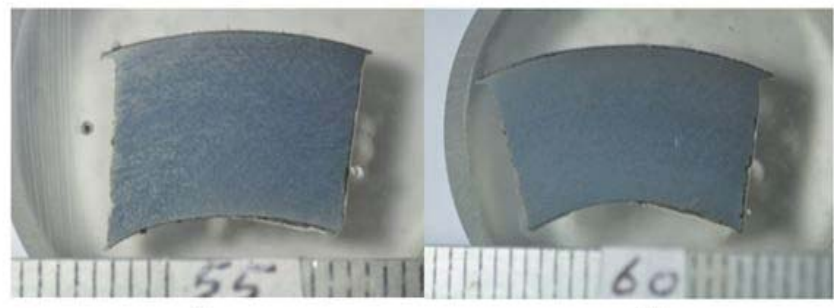

(a)

(b)

Figure 7: Micro photo material samples and radius hardness test (a) $55 \mathrm{~mm}$ and (b) $60 \mathrm{~mm}$

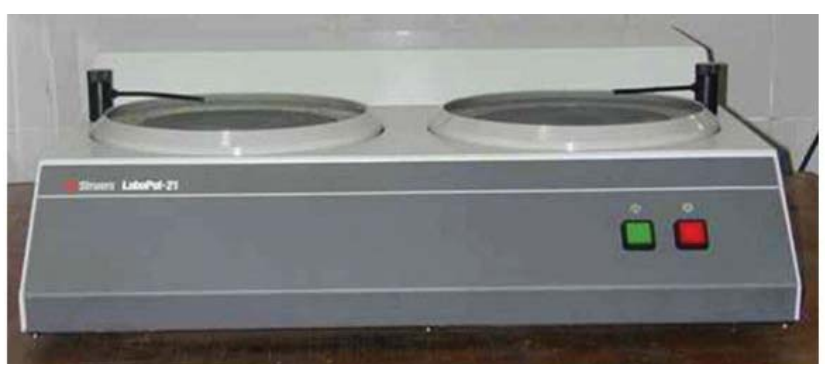

Figure 8: Grinding machine

Table 1: Chemical composition of sheet material ( mass percent, \%)

\begin{tabular}{|l|l|l|l|l|l|l|l|l|l|}
\hline Al & $\mathrm{C}$ & $\mathrm{Cr}$ & $\mathrm{Cu}$ & $\mathrm{Fe}$ & Mn & Mo & Ni & $\boldsymbol{P}$ & $\boldsymbol{P b}$ \\
\hline 0.0378 & 0.2934 & 0.5503 & 0.0833 & 96.7625 & 1.4121 & 0.1930 & 0.2787 & 0.0142 & 0.0082 \\
\hline $\mathrm{S}$ & $\mathrm{Si}$ & $\mathrm{Sn}$ & $\mathrm{Ti}$ & $\mathrm{V}$ & $\mathrm{W}$ & & & & \\
\hline 0.0081 & 0.3298 & 0.0034 & 0.0044 & 0.0147 & 0.0095 & & & & \\
\hline
\end{tabular}


Table 2: Hardness value Hot Rolled Plate Steel

\begin{tabular}{|c|c|}
\hline The test object code & (VHN) \\
\hline $\mathrm{HN}_{\mathrm{HRC}}$ & 275,220 \\
\hline
\end{tabular}

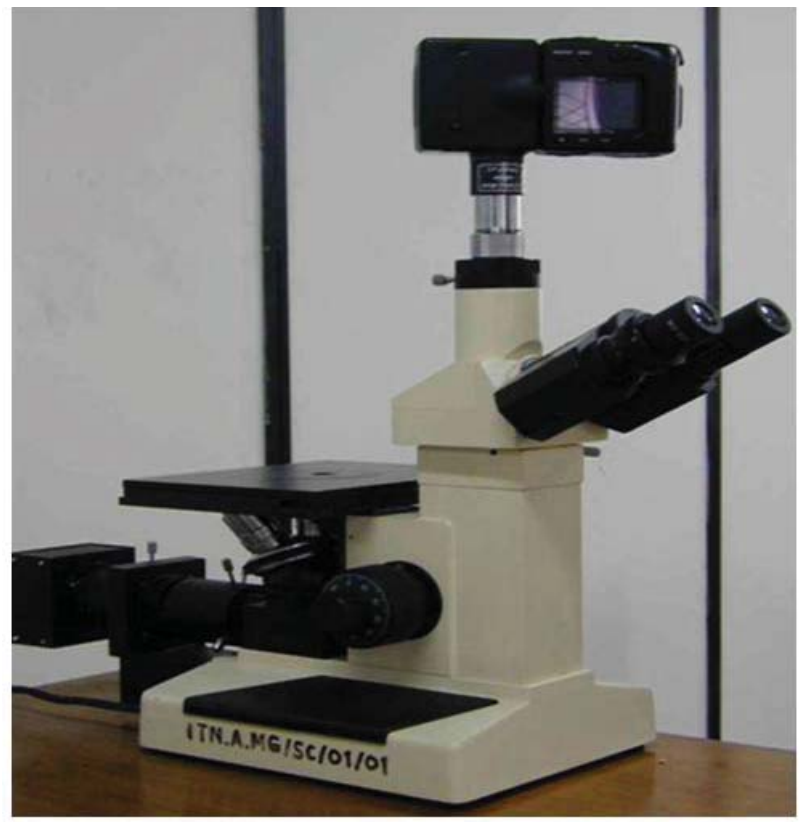

Figure 9: Photo Micro

due to the bending force, so that the bending area of hardness at HRP Steel becomes high due to the density of ferrite structures. When connected with figure 5 before bending ferrite structure density at $55 \mathrm{~mm}$ bending is more dense. This will affect the nature of violence on HRP Steel. If proven by figure 11 the value of bending at $55 \mathrm{~mm}$ is higher than HRP Steel before getting bending treatment.

In Figure 10.b, the density of the ferrite structure is more tenuous compared to HRP Steel before bending treatment and after $55 \mathrm{~mm}$ bending treatment. So that the value of hardness at HRP Steel bending $60 \mathrm{~mm}$ is below HRP Steel before bending treatment and after $55 \mathrm{~mm}$ bending treatment, this is evidenced by figure 11. At HRP Steel bending $60 \mathrm{~mm}$ when giving ferrite structural force moves the given bending force, because the bending force is too large given the density of the ferrite structure at the center point becomes high and will move back to the empty space that is moving away to the area near the center of the force. Actually, at $60 \mathrm{~mm}$ bending this is a re-alignment of ferrite structures from the center of the bending area to areas that are far from the center of bending. But the weakness of bending $60 \mathrm{~mm}$ which is done by bending center area has a lower hardness value than bending $55 \mathrm{~mm}$.

In bending treatment, the microstructure in HRP Steel does not experience phase changes. Changes in microstructure that occur in bending treatment only on the movement of ferrite and pearlite structures. This is because in the bending treatment there is no heat treatment. The cause of the phase change of microstructure in steel is due to heat treatment as described in the Fe-C diagram (figure 1). The occurrence of phase changes in the ferrite structure to the austenite structure phase only occurs in the heat treatment temperature of $723^{\circ} \mathrm{C}$.

\section{Effect of Heat Treatment on HRP Steel Microstructure.}

Basically theoretically taken from previous research, the heat treatment given to a material can improve the physical properties and mechanical properties of the material. In addition to the heat treatment process temperature, the phase change in the structure is affected by cooling time (figure 12).

Figure 12 shows the cooling time after heating to austenizing temperature, where in figure 12 (b) cooling using water media will form the structure of austenite and martensite, cooling the oil media will form the structure of ferrite, perlite, austenite, bainite and martensite while with air media form the structure of ferrite, perlite and austenite [15].

This study, HRP steel material that has been bent with a radius of $55 \mathrm{~mm}$ and $60 \mathrm{~mm}$ was given heat treatment to improve the material properties, especially violence. The heat treatment carried out was quenching (temperature $800{ }^{\circ} \mathrm{C}$ with a holding of 15 minutes and tempering (quenching temperature $800{ }^{\circ} \mathrm{C}$ with holding 15 minutes followed by heating $150{ }^{\circ} \mathrm{C}$ with 45 minutes holding).

Figure 13 shows the difference in quenching heat treatment at different bending that is $55 \mathrm{~mm}$ and $60 \mathrm{~mm}$ changes in structure. The microstructure formed in the quenching heat treatment of austenite and martensitic structures Figure 13 (b) the shape of austenite is large compared to figure 13 (a) so that it will affect the percentage of martensite bending treatment $55 \mathrm{~mm}$ (fig. $13 \mathrm{a}$ ) the percentage of martensite is greater so that the vickers

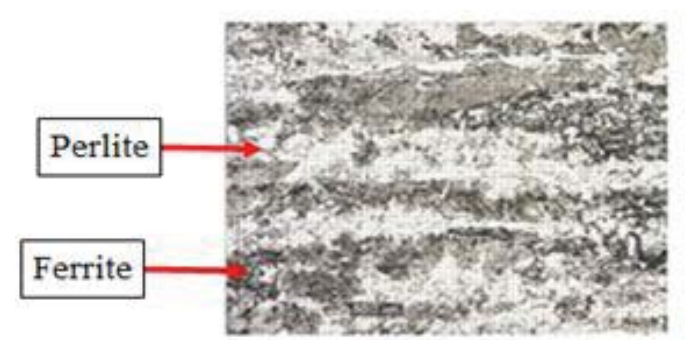

(a)

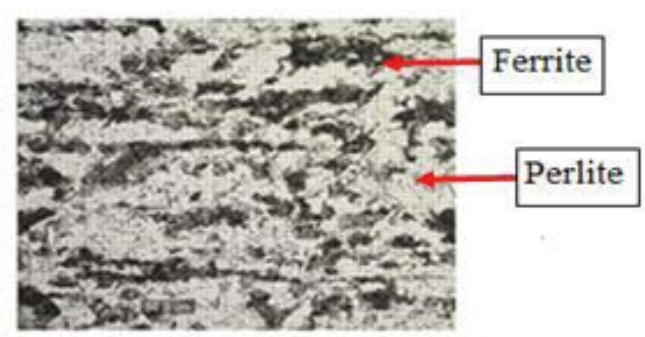

(b)

Figure 10: Microstructur HRPS after heat treatment a) Bending $55 \mathrm{~mm} \mathrm{b)} \mathrm{Bending} 60 \mathrm{~mm}$ 


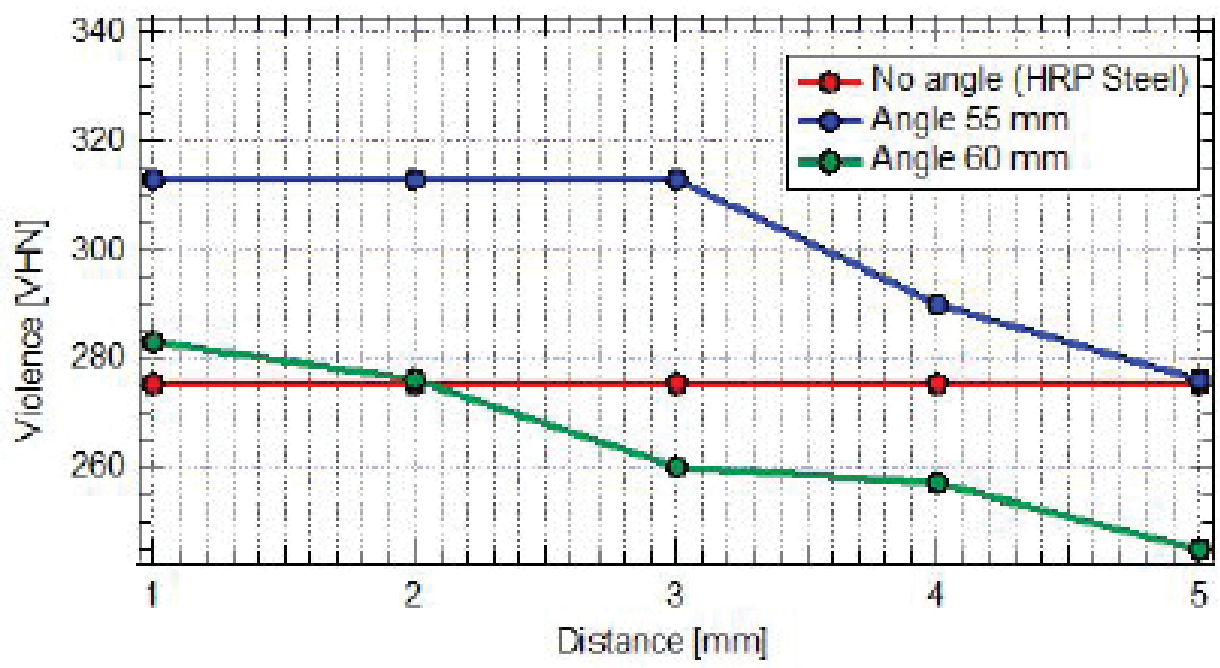

Figure 11: Hardness Vickers HRP Steel Bending 55mm and 60mm

hardness value has a greater value than $60 \mathrm{~mm}$ bending treatment. This is because the bending treatment $55 \mathrm{~mm}$ before the treatment has a solid structure in the bending area so that when quenching heat treatment more martensitic structures are formed and the structure is denser than $60 \mathrm{~mm}$ bending treatment. Therefore, after quenching treatment the value of Vickers bending hardness is $55 \mathrm{~mm}$ higher than $60 \mathrm{~mm}$ bending (fig. 15).

Figure 14 is microstructure morphology after quenching-tempering heat treatment. In this figure the martensite structure is formed finer and denser than quenching heat treatment. By comparing figure. 13 and figure. 14, that the martensite structure is formed more and finer. This is because in the quenching process, tempering occurs again after quenching treatment. This reheating aims to give time to phase changes in the martensite structure to be more evenly distributed. This reexamine figure 12 that the cooling process using aqueous media will form austenite and martensite but with extreme cooling like this the formed structure looks rough and uneven so that reheating is carried out under austenizing temperature

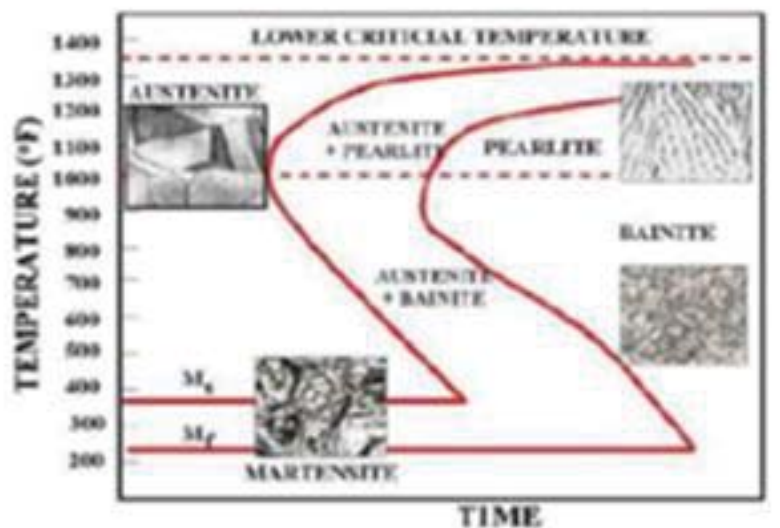

(a) to give time to improve the structure formed by treatment heat with austenizing temperature. Because the holding time in quenching - tempering is longer so the process of forming martensite structures is more perfect.

With this change in martensitic structure in quenching tempering it will significantly affect the hardness value of the vickers material. It is evident in Figures 14 and 15 that, quenching-tempering heat treatment has a higher hardness value than quenching heat treatment and without heat treatment. From the results of this study it can be concluded that the heat treatment of HRP Steel affects the shape of microstructure. So that with changes in the micro structure that occurs, the value of violence will change.

\section{CONCLUSION}

From the results of the morphological analysis, it can be concluded that the bending radius and heat treatment of the material affect the microstructure which formed the material so that the vickers material hardness values will increase. Seeing the results of the present research, a

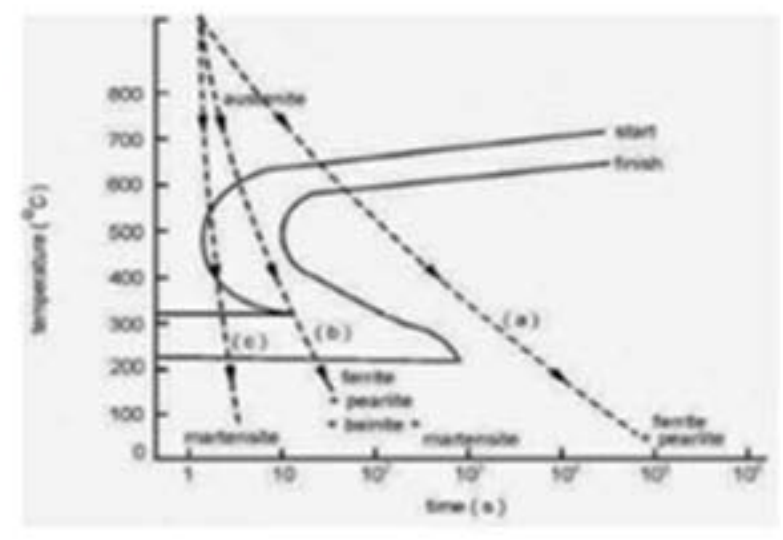

(b)

Fig.12 (a) Time Temperature Transformation (b) Diagram of Continuous Cooling Temperature 


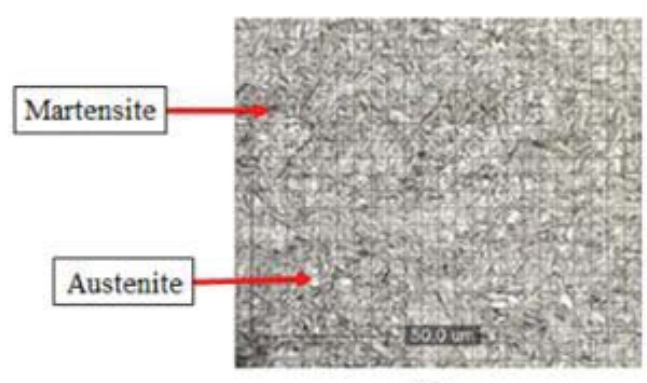

(a)

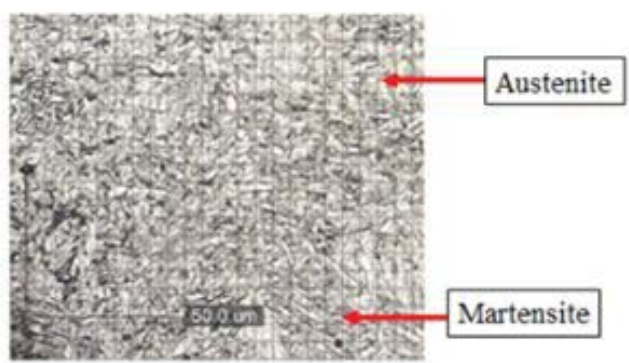

(b)

Fig.13 Microstructure HRPS after Quenching $800{ }^{\circ} \mathrm{C}$ (a) bending $55 \mathrm{~mm}$ (b) bending $60 \mathrm{~mm}$

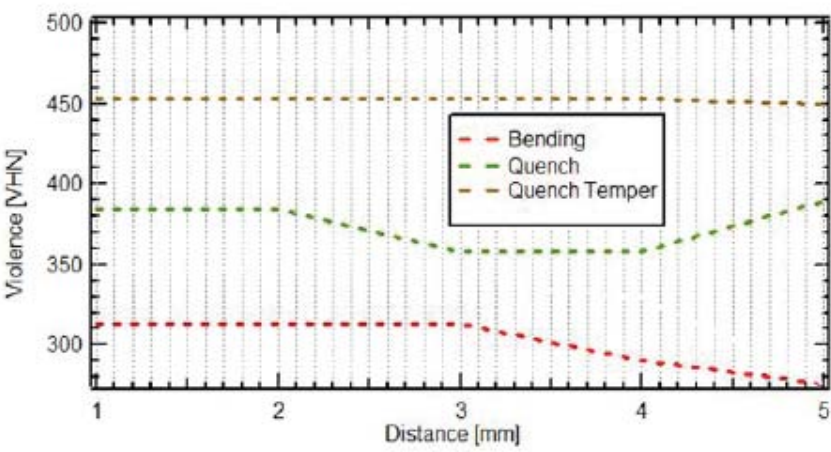

Fig.14 Vickers Hardness Bending $55 \mathrm{~mm}$

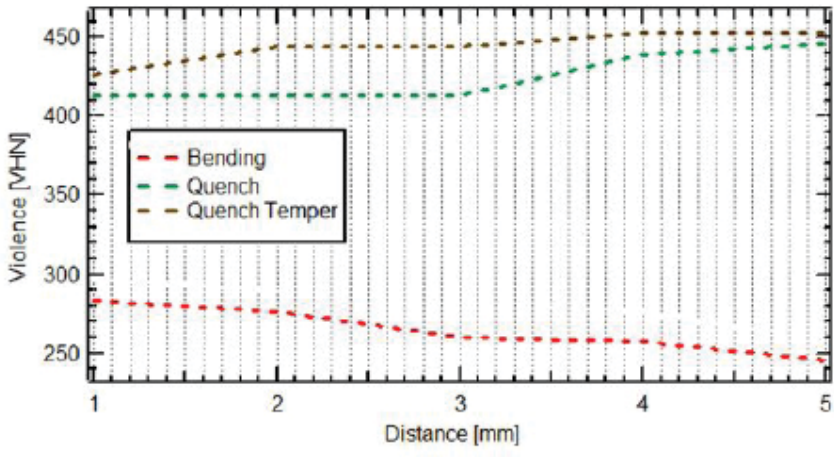

Fig.15 Vickers Hardness Bending $60 \mathrm{~mm}$

bending radius that can be used is a $55 \mathrm{~mm}$ bending radius with quenching-tempering heat treatment. Because this treatment has a more dense and smooth martensite structure, so the value of violence will be higher than other treatments that have been done in this study.

\section{ACKNOWLEDGMENTS}

The author would like to thank for their financial support of this work :

Directorate of Research and Community Service. Directorate General of Research and Development Reinforcement, Ministry of Research, Technology and Higher Education, in accordance with Research Contract No. SP DIPA: 042.06.1.401516/2017, Date 07 December 2016. And Prof.Dr.Ir. Pratikto, MMT as Principal Counselor, Prof. Ir.Agus Suprapto, Meng., PhD , Co Promotor1 and Dr.Ir. Achmad As'ad Sonief, MT Co. Promotor2.

Results Discussions / Suggestions by: Prof.Ir. Rochim
Suratman, MEng., PhD (Technical Head of PT PINDAD) Ir. Amung Sumantri, MM (Product Development Maneger of PT Krakatau Steel)

\section{REFERENCES}

1. Cimpoeru, S. J. (2016) The Mechanical Metallurgy of Armours Steel. Defence Sains and Technology Group - Land Division. Australia.

2. G. Madhusudhan Reddy, T. Lee, G.R.N. Tagore, (1995) Weldability studies of high-strength low-alloy steel using austenitic fillers, Journal of Materials Processing Technology 49, $213-228$

3. Su J. Et al, (2013) Simulation Analysis of Minimum Bending Radius for Lead Frame Copper Alloys, Journal of Material Science and Engineering 101106, China

4. Krauss, R.M., \& Hadar, U. (1999). The role of speech-related arm/hand gestures in word retrieval. In, R. Campbell \& L. Messing (Eds.), Gesture, speech, and sign $(93-116)$. Oxford: Oxford University Press.

5. Zuo X, Zhou Z. (2015) Study of Pipeline Steels with Acicular Ferrite Microstructure and Ferrite-bainite Dual-phase Microstructure. Materials Research. 18 (1):36-41.

6. Pereloma EV, Kostryzhev AG, AIShahrani A, Zhu C, Cairney JM, Killmore CR, et al. (2014) Effect of austenite deformation temperature on $\mathrm{Nb}$ clustering and precipitation in microalloyed steel. Scripta Materialia, 75:74-77.

7. Tian $Y$, Tang S, Wang BX, Wang ZD, Wang GD, (2012) Development and industrial application of ultra-fast cooling technology. Science China Technological Sciences, 55(6):1566-1571

8. Ravikumar SV, Jha JM, Mohapatra SS, Pal SK, Chakraborty S. (2013) Influence of Ultrafast Cooling on Microstructure and Mechanical Properties of Steel. Steel Research International. 84(11):11571170.

9. Wang G, Yan Y, Li J, Qiao L, Volinsky AA, (2013). Microstructure effect on hydrogen-induced cracking in TM210 maraging steel. Materials Science and Engineering, 586:142-148. 
10. Briant, C.L.; Banerji, S.K, (1979) Tempered martensite embrittlement in phosphorus doped steels. Metall. Trans. A, (10), 1729-1737

11. Fang $X$, Fan Z, Ralph $B$, Evans $P$, Underhill $R$, (.2003) Effects of tempering temperature on tensile and hole expansion properties of a C-Mn steel.Material Processing Tecnology, (132) ;215-218

12. Sharifi H, I Kheirollahi-Hosseinabadi, Ghasemi R., (2015) The Effect of Tempering Treatment on the Microstructure and Mechanical Properties of DIN 1.4021 Martensitic Stainless Steel. International Journal of ISSI , (12) 1; 9-15

13. Adamczyk J, Grajcar A, (2017) Heat treatment and mechanical properties of low-carbon steel with dual-phase microstructure. Journal of Achievements in Materials and Manufacturing Engineering, (22) 1; 13-20

14. Daramola O. Oluyemi, Oladele Isiaka Oluwole, Adewuyi B. O, (2011) Studies of the Properties of Heat Treated Rolled Medium Carbon Stee. Materials Research. 14(2): 135-141

15. Handoyo, Yopi, (2015) Pengaruh Quenching dan Tempering Pada Baja JIS Grade 245C Terhadap Sifat Mekanis. Jurnal IImiah Teknik Mesin Universitas Islam Bekasi. Vol. 3, No. 2, Hal 102-115. 